\title{
An over-the-counter central sensitization therapy: a chronic back pain registry study of pain relief, medication use and their adverse effects
}

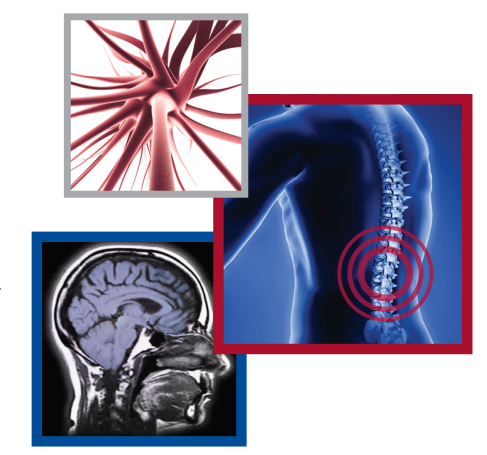

Richard Staelin', Sree N Koneru' ${ }^{2,3}$ \& lan M Rawe $e^{*, 2}$

Practice points

- Subjects in this study had chronic back pain (CBP), with a mean pain duration averaging 6.1 years.

- Pain etiologies demonstrated a heterogeneous subject population of CBP sufferers.

- About $96 \%$ of the subjects were using analgesics medications averaging 2.5 per subject, with $71 \%$ using prescription analgesics.

- The majority of individuals using analgesic medications for CBP report less than adequate pain relief.

- Adverse effects from pain medications are common (66\%) for CBP sufferers.

- CBP sufferers, who report chronic pain for longer than 2 years, also detail using approximately $25 \%$ more prescription analgesics than those who have experienced the pain for less than 2 years.

- The number of adverse effects is directly proportional to the number of prescription analgesics being used.

- The increase in the number of adverse side effects negatively impacts quality of life.

- The majority of CBP users, upon using the ActiPatch ${ }^{\circledast}$, reported a clinically significant reduction in pain within 7 days.

- Nearly $50 \%$ of the study subjects were able to eliminate or decrease analgesic medications after 7 days of use of the medical device.

- The ActiPatch was effective in reducing CBP for the majority of subjects as well as reducing their analgesic use.

Aim: Back pain, the most prevalent musculoskeletal chronic pain condition, is usually treated with analgesic medications of questionable efficacy and frequent occurrence of adverse side effects. Objective: The objective was to determine the effectiveness of the ActiPatch medical devices in reducing chronic back pain, document medication related adverse side effects and establish their impact on quality of life. Methods: Upon completing a 7-day trial, subjects were contacted via email with an assessment form using the Constant Contact email program. A total of 1394 responses were collected from subjects who used the device for back pain. Conclusion: Medication adverse effects are common and impact quality of life in the lay population. ActiPatch is an effective intervention for the majority of subjects for treating chronic back pain, although this requires further investigation in randomized clinical trials.

First draft submitted: 27 September 2016; Accepted for publication: 23 November 2016; Published online: 2 December 2016
Future $\because \cdots$ Medicine $\%$ part of 


\section{KEYWORDS}

- adverse side effects

- analgesics • chronic back pain $\bullet$ medication reduction - pain relief - pulsed shortwave therapy (PSWT)
Chronic pain, defined as pain which has persisted for greater than 3 months, is a widespread and complex condition [1]. Over $40 \%$ of all chronic musculoskeletal pain conditions are associated with chronic back pain (CBP) $[2,3]$ and $\mathrm{CBP}$ has been documented to present a significant financial and emotional burden both to the individual and society $[2,4-6]$. Treatments that are ineffective and poorly tolerated can drive up direct healthcare costs [7]. Although delivering effective therapy for CBP is challenging, the most successful approach is to utilize a multimodal treatment program that necessitates management by a multidisciplinary team of healthcare specialists [8-10].

Currently, most chronic pain sufferers rely heavily on both over-the-counter (OTC) and prescription analgesic medications to treat their pain. The OTC analgesics include acetaminophen (paracetamol) [11] and NSAIDs [12], while prescription drugs include tricyclic antidepressants [13], serotonin and norepinephrine re-uptake inhibitors [14], corticosteroids [15], anticonvulsant $[16,17]$ as well as opiate pain relievers [18]. A major drawback of analgesics, especially of prescription origin, is the significant number of adverse effects that often negatively impact the quality of life (QoL) [19-21]. A US Pain Foundation study showed that $45 \%$ of users of OTC drugs do not fully realize the implications of the prescription drugs they are taking and $65 \%$ do not consider the possible interactions of other OTC medications they are taking [22]. Moreover, analgesic medications are often ineffective for many individuals [23]. A recent survey by Arthritis UK [24] indicates that only $46 \%$ of respondents were satisfied with their pain management, with up to $80 \%$ reporting that their mobility was still affected and $64 \%$ reporting difficulties in sleeping from a lack of pain relief. Although these facts are well known, the full extent of the adverse effects resulting from the use of multiple analgesics and their impact on QoL in the lay population has not been well documented. This is a central objective of this study.

Safer, more effective alternatives for CBP are now emerging. One such alternative is the ActiPatch, which is a commercially available medical device in the UK, Canada and parts of Europe that uses pulsed shortwave therapy (PSWT) [25] to provide relief from chronic pain $[26,27]$. Randomized, double-blind, placebocontrolled studies that utilized the ActiPatch indicate clinically significant decreases in pain, along with a decrease in the use of medication [2628 . For example, in a 4-week study investigating osteoarthritis of the knee [26], 26\% of subjects in the ActiPatch treatment group stopped the use of prescribed analgesics, mainly NSAIDs, while $0 \%$ added a new therapy for pain management. In comparison, only $3 \%$ of the subjects in the control group reported eliminating analgesics, while $33 \%$ initiated a new therapy for pain management.

In a previously published, 5000 cohort registry study [29] that investigated general chronic pain, subjects reported high levels of baseline pain (8.03 visual analog scale [VAS] pain score) despite the wide, and often multiple use of analgesic medications in addition to other modalities such as transcutaneous electrical nerve stimulation (TENS) and heat wraps. After using a special trial device that lasts for 7 days, $65 \%$ of chronic pain subjects reported effective pain relief, defined as a decrease of $\geq 2$ points on the VAS pain scale over this 7-day period. Of those reporting effectiveness, baseline pain was reduced from $8.17 \pm 1.50$ to $3.49 \pm 1.98$, or a $57 \%$ pain decrease.

The current study investigates the effectiveness of this 7-day trial ActiPatch device for CBP by assessing a new cohort of subjects. In addition, the study collects data on a wider analgesic profile, a rating of how effective these medications are, the fraction of users who report adverse effects, the details of these adverse effects and how likely it was for the CBP sufferer to reduce medication use after using the medical device for 7 days. In all, 1394 subjects were part of this study.

\section{Methods}

\section{- Subjects}

A registry of 31,125 subjects was established between January and May 2016 who tested a 7-day trial device, ActiPatch ${ }^{\circledR}$ (BioElectronics Corporation, MD, USA) for musculoskeletal pain after responding to formal company messaging or recommendation from family or friends. There were no formal inclusion/exclusion criteria, except for the contraindications of the medical device (women, who are pregnant, and children) and pain duration greater than 6 months. All the subjects in this study were from the UK and Ireland where the device is classified as class IIa and sold OTC as a pain therapy. The subjects paid a fee for the device which was shipped to their home. Email addresses were collected in the ordering process. A trial completion date was estimated based on the sample 
order data, following which an assessment was emailed to the subjects using Constant Contact (Constant Contact, MA, USA) email marketing software (see Supplementary Materials for assessment details). A second reminder email was sent 4 days after the first email. Subjects' response to the email survey was completely voluntary, and no other method was used to collect the data. The assessment was designed to collect data on age, gender, pain level, duration of pain, location and cause of pain, as well as analgesic profile, adverse effects* reported, the effect of adverse events on QoL on a $0-10$ scale ( 0 being no effect and 10 being the worst effect) and any change in medication after using the medical device.

*A list of adverse effects was provided in the assessment form, where respondents could select one or more applicable adverse effects. This list was created after observing responses from the first 400 subject assessments in this study, where subjects were allowed to comment on the adverse side effects they were experiencing.

\section{- ActiPatch}

ActiPatch is a low power PSWT device that is classified as an OTC, class II(a) medical device in the EU. The device operates at a carrier frequency of $27.12 \mathrm{MHz}$ and pulses 1000-times per second, each sustained for a duration of 100 $\mu s$. There are two versions of the device. The 7-day trial device has no on/off switch and the battery life is approximately $168 \mathrm{~h}$ or 7 days (cost $\mathfrak{1 5}$ ). This trial device comes with medical adhesives that allow the user to attach the device to the skin (or a thin piece of clothing) and is to be applied over the area of pain. The OTC retail device last for $720 \mathrm{~h}$ and has on/off capability, and is supplied with a choice of a back wrap medical adhesive tape (Supplementary Figure 1). The retail device sells for $£ 23$. The wraps have a pocket designed for the device and straps with Velcro fastening to secure the device in place.

\section{- Data handling}

Data from the responses were exported as a comma-delimited (CSV) file, and analyzed using Microsoft Excel (Microsoft Corporation, WA, USA) and an Excel add-on (Regressit). Cross tabs and multivariate regression analysis were used to explore the relationship between a number of characteristics of the subjects and adverse side effects, a person's QoL and medication use and change in medication use.

\section{Results}

- Demographics

Of the 31,125 users who were contacted, over a 5-month period (from January to May 2016), approximately $40 \%$ opened the email and $32 \%$ of these people agreed to 'consider being part of the registry' by clicking onto the link to the assessment. Of those who consented, 88\% completed the assessment resulting in a total response of 3735 individuals and an overall response rate of $12 \%$. Of this group, 1394 subjects indicated that they used the device for CBP. The gender, age and duration of pain distributions are given in Tables 1 \& 2. In general, the sample was predominately a woman, over 35 years of age and experiencing long-standing pain of 2 or more years with a median of 6.1 years.

Etiologies reported by the study subjects (Table 3) demonstrate that the population was heterogeneous and, on average, subjects reported pain caused by 1.57 etiologies, and some of these are therefore not related to CBP.

\section{- Analgesics}

The most commonly used analgesics were NSAIDs (46\%) and paracetamol (52\%), followed by weak opioids (typically tramadol) at $30 \%$ and amitriptyline at $29 \%$. In addition, many CBP sufferers indicated that they were using other treatment modalities such as TENS, heat wraps and physical therapy (Table 4). On average, each subject using medications in the study used 2.5 analgesics, including topical analgesics (NSAIDs or opiate). Only 3.7\% reported not using analgesics.

Subjects were asked to rate the pain relief they experienced from pain medications (Figure 1). Only $7.5 \%$ reported good pain relief, while $31.8 \%$ reported adequate pain relief, leaving $60.4 \%$ who reported less than adequate pain relief or no real pain relief. The mean number

\begin{tabular}{|c|c|}
\hline Gender & $n=1394(\%)$ \\
\hline Male & 25 \\
\hline Female & 75 \\
\hline \multicolumn{2}{|l|}{ Age (years) } \\
\hline $18-24$ & 1.4 \\
\hline $25-34$ & 3.4 \\
\hline $35-44$ & 14.9 \\
\hline $45-54$ & 29.4 \\
\hline $55-64$ & 27.6 \\
\hline 65 or more & 22.4 \\
\hline
\end{tabular}




Table 2. Duration of pain.
\begin{tabular}{|ll|}
\hline Pain duration & $\mathrm{n}=1394(\%)$ \\
\hline 6 months to 1 year & 7.6 \\
\hline $1-2$ years & 21.9 \\
\hline $2-5$ years & 24 \\
\hline $5-10$ years & 21.2 \\
\hline $10-20$ years & 18.4 \\
\hline 20 years + & 16 \\
\hline
\end{tabular}

of analgesics used for those reporting good pain relief was 2.34 (1.52 prescription, 0.82 OTC), 2.48 (1.46 prescription, 1.02 OTC) for adequate pain relief, 2.6 (1.52 prescription, 1.08 OTC) for less than adequate pain relief and $2.42(1.82$ prescription, 0.6 OTC) for no real pain relief.

\section{- Pain data}

The mean baseline pain reported by the CBP subjects before using the medical device was $8.04 \pm 1.46$ (Figure $2 \&$ Table 4). The pain score, post-trial was $4.83 \pm 2.66$, or a $39.9 \%$ decrease ( $p<0.001)$. The percent of subjects that reported effectiveness, defined as a minimum of $40 \%$ pain decrease, was $52 \%$ (Table 5). These positive responders reported a mean pain decrease of 5.40 VAS points, or $66 \%$ reduction in pain. Conversely, 26\% reported no improvement in

\begin{tabular}{ll|}
$\begin{array}{l}\text { Table 3. The reported etiologies show a } \\
\text { heterogeneous pain population. }\end{array}$ \\
\hline Etiology & $\%$ \\
\hline Not sure what causes my pain & 11.5 \\
\hline Accident & 7.0 \\
\hline Ankylosing spondylitis & 4.2 \\
\hline Cervical issues & 2.3 \\
\hline Complex regional pain syndrome & 1.1 \\
\hline Disc issues & 18.0 \\
\hline Fibromyalgia & 11.8 \\
\hline Frozen shoulder & 0.9 \\
\hline Ligament damage & 1.4 \\
\hline Multiple sclerosis & 0.6 \\
\hline Neuropathy & 2.4 \\
\hline Osteoarthritis & 13.7 \\
\hline Osteoporosis & 2.5 \\
\hline Rheumatoid arthritis & 6.1 \\
\hline Sciatica & 11.8 \\
\hline Sports injury & 1.3 \\
\hline Surgery & 3.0 \\
\hline Tendinitis & 0.9 \\
\hline Tennis elbow & 1.1 \\
\hline Trapped nerve & 4.4 \\
\hline Other & 5.9 \\
\hline
\end{tabular}

pain levels, while $1.5 \%$ reported an increase in pain.

\section{- Continuation of therapy}

Intent to continue the use of the device by subjects was determined, this ranged from 'definitely' to 'definitely not' (Table 6). Intent was closely associated with the degree of VAS reduction with those reporting the greatest VAS reduction indicating a 'definite' intent, whereas those reporting no pain relief indicated 'definitely not' intent to continue the therapy.

\section{- Changes in analgesic medication use}

Data were also collected on any changes in analgesic medication use over the 7-day period (Figure 3). The available responses and percent response were increased medication use $(0.6 \%)$, added a new therapy $(0.3 \%)$, decreased medication use (36\%), eliminated medications (14\%) and made no change (49\%).

\section{- Analgesic adverse effects - QoL}

The impact of analgesic adverse effects on QoL of subjects was assessed on a $0-10$ scale ( 0 being no effect and 10 being the worst effect). A total of 996 or $71.4 \%$ of the 1394 CBP subjects were asked about possible adverse effects associated with their medication use. Of these individuals, $66.1 \%$ (658) reported adverse effects. In total, there were 3010 adverse effects reported by this group, with the most frequent being constipation (332), followed by dry mouth (279), drowsiness (273), sleep problems (237) and weight gain (191) (see Figure 4). The mean number of adverse effects was $4.6 \pm 3.3$ per person, for those 658 subjects reporting adverse effects. When asked how adverse effects negatively impacted the QoL on a $0-10$ scale, the mean reported was $5.7 \pm 2.8$.

\section{- Analgesics use - relation to pain duration}

The percent of people reporting adverse effects, the number of adverse effects and the impact of these medications on the QoL are segmented by the duration of pain in Table 7. These results indicate that there are significant correlations between duration of pain, the use of analgesics and the number of reported adverse side effects. This is driven in part by the use of prescription analgesics which is seen to increase from approximately 1.1 per individual in the two groups with the shortest pain duration (0-6 months and 6 months to 2 years) to a mean of 1.45 per individual at the 2-5year pain duration, before peaking for the 5-10 
year group at a mean of 1.74 per individual. The percent of subjects experiencing adverse effects is less than $50 \%$ when the pain duration is 2 years or less, but it increases to $68.3 \%$ with a pain duration of 2-5 years and continues to increase with pain duration, even though prescription use decreases for the longer levels of pain duration. This indicates that pain duration could influence the number of adverse effects in individuals above and beyond to any use of prescription drugs. Finally, we see a comparable increase in the negative impact of pain on the QoL, increasing by almost $50 \%$ from the shortest pain duration to the longest pain duration (Table 7).

\section{- Analgesics use \& QoL - relation to age}

Analgesic use, adverse effects and their impact on QoL are categorized by age of the subjects (Table 8). It is interesting to note that younger age groups report using higher rates of medications and consequently experience a higher number of mean adverse effects as well as greater impact on QoL. The 25-34-year age group has the highest analgesic use and experienced the highest number of adverse effects per individual. A reduction in both these factors is seen with increasing age. Thus, the oldest age group, 65 years plus, has the lowest medication use and consequently the lowest mean adverse effects and lowest impact on QoL. There was no significant statistical relationship between age and duration of pain, in other words, older subjects are not more likely to have a longer duration of pain. Thus, these two variables should be thought of as being independent.

\begin{tabular}{|c|c|}
\hline Analgesic & $\%$ \\
\hline Paracetamol (acetaminophen) & 52 \\
\hline NSAIDs & 46 \\
\hline Weak opioids (codeine, tramadol) & 30 \\
\hline Strong opioids & 13 \\
\hline Cox-2 inhibitors & 1 \\
\hline Pregabalin (e.g., Lyrica) & 13 \\
\hline Amitriptyline & 29 \\
\hline Topical opioid (e.g., morphine) & 10 \\
\hline Topical NSAIDs (e.g., Voltarol) & 17 \\
\hline Gabapentin & 16 \\
\hline Duloxetine (e.g., Cymbalta) & 1 \\
\hline Steroids (e.g., prednisone) & 2 \\
\hline Epidural & 2 \\
\hline Other & 7 \\
\hline No analgesics & 3.7 \\
\hline \multicolumn{2}{|l|}{ Other modalities } \\
\hline TENS & 24 \\
\hline Heat wraps & 30 \\
\hline Physical therapy & 20 \\
\hline
\end{tabular}

\section{Regression analysis}

- Side effects \& therapy

The relationship between the number of reported side effects and the quantities of the different types of therapy being used was explored. These were the number of different OTC medications, the number of different prescription drugs and the number of different other treatments (e.g., TENS and heat wraps) where larger

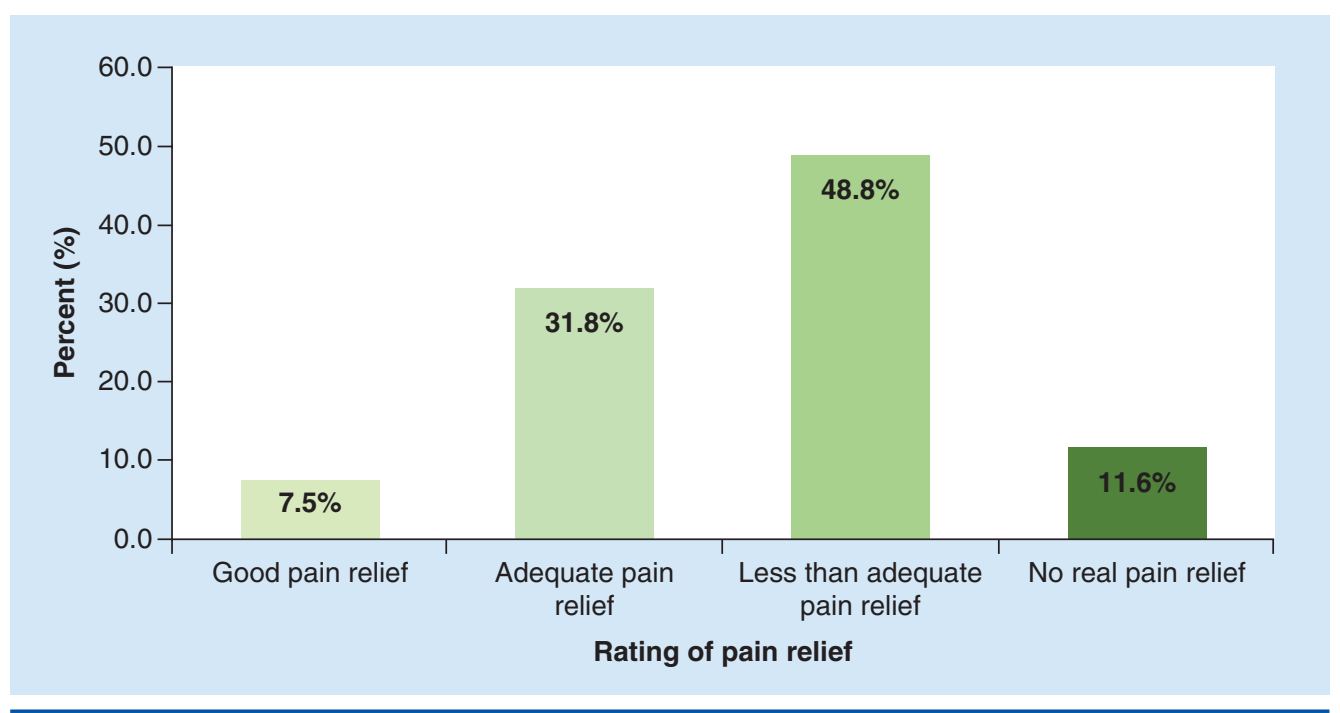

Figure 1. Ratings of pain relief by subjects indicate that only $7.5 \%$ get good pain relief, with $60.4 \%$ experiencing less than adequate pain relief. 


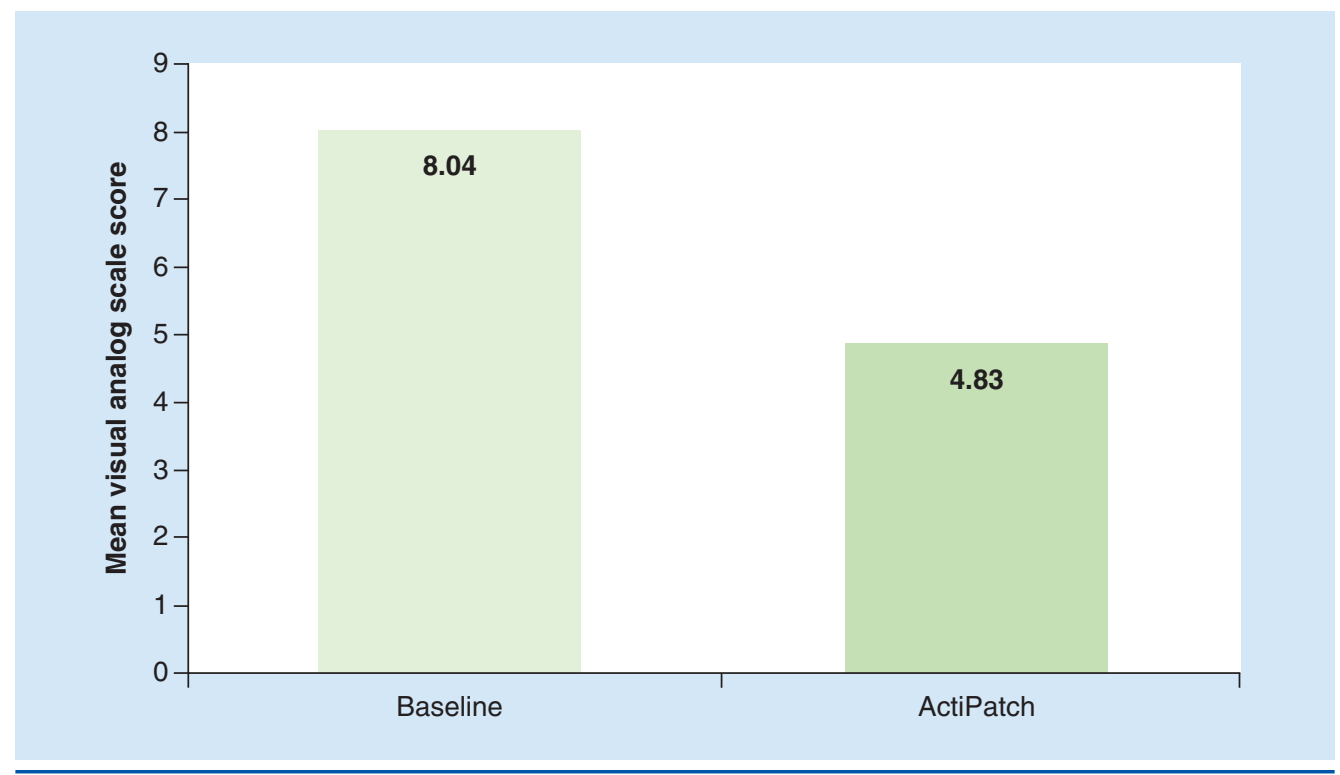

Figure 2. Visual analog scale scores at baseline and after device use shows a mean pain reduction of $39.9 \%$ across all the chronic back pain subjects in the study.

numbers for each therapy indicate that the subject was using more types of the particular therapy. A number of control variables were included, these being age, gender, duration of the pain and baseline pain. All the variables in this multivariate regression were significant $(\mathrm{p}<0.02)$ except age and gender. However, the most significant variable as measured by the standardized coefficients was the number of prescription drugs taken $(\mathrm{p}<$ 0.0001 ). The estimated coefficients for the regression analysis were that a reduction of one prescription drug would result in an estimated reduction of 1.45 side effects per subject. In contrast, the reduction of one OTC medication would only result in a reduction of 0.35 side effects per individual, indicating that the prescription drug effect is four-times greater than OTC medication.

\section{- Side effects \& QoL impact}

The next regression has QoL as the dependent variable where higher numbers indicate a greater negative impact on the person's QoL. A number of control variables were included, these being age, gender, duration of pain, reduction in the use of medications after using the medical device and the reported reduction in pain as measured by the difference between before and after pain levels. The number of side effects was found to have a strong, negative impact on a subject's QoL $(p<0.0005)$. The only other variable significant at $\mathrm{p}<0.05$ was the reported decreases in medication use. Subjects who reported a greater medication reduction were less likely to report a negative effect on the QoL. Decreases in the person's level of pain were not significant after controlling for the number of side effects reported and the reduction of medication.

\section{- Reduction in pain \& medications taken}

The data show that using the medical device for 7 days is associated with subjects reducing their pain levels and also reducing medication use (Figures $2 \& 3$ ). This relationship was quantified through regression analysis, where the

Table 5. The percent of individuals who reported a $40 \%$ or greater visual analog scale scores reduction was $726 / 1394$ or $52 \%$.

\begin{tabular}{|lll|}
\hline Pain measure & All $\mathbf{n}=1394$ & Effective $\geq 40 \%$ pain reduction $\mathbf{n}=\mathbf{7 2 6}(\mathbf{5 2} \%)$ \\
\hline Baseline VAS & $8.04 \pm 1.46$ & $8.16 \pm 1.41$ \\
\hline Post-trial VAS & $4.83 \pm 2.68$ & $2.76 \pm 1.40$ \\
\hline VAS difference & 3.21 & 5.40 \\
\hline $\begin{array}{l}\text { Percent reduction (\%) } \\
\text { p-value }\end{array}$ & 39.9 & 66.2 \\
\hline $\begin{array}{l}\text { These individuals had a mean pain reduction of } 66 \% . \\
\text { VAS: Visual analog scale. }\end{array}$ & $\mathrm{p}<0.001$ \\
\hline
\end{tabular}




Table 6. The intent to continue therapy.
\begin{tabular}{|lllll|}
\hline Intent & Percent & Baseline VAS & Trial VAS & VAS difference \\
\hline Definitely & 40.6 & $8.34 \pm 1.40$ & $3.09 \pm 1.93$ & 5.25 \\
\hline Probably & 13.4 & $7.92 \pm 1.39$ & $4.02 \pm 1.96$ & 3.90 \\
\hline Possibly & 14.8 & $7.80 \pm 1.58$ & $5.25 \pm 2.16$ & 2.55 \\
\hline Probably not & 16.3 & $7.67 \pm 1.38$ & $6.70 \pm 1.99$ & 0.97 \\
\hline Definitely not & 14.9 & $8.00 \pm 1.49$ & $7.87 \pm 1.75$ & 0.13 \\
\hline VAS: Visual analog scale. & & & \\
\hline
\end{tabular}

dependent variable is medication reduction. This variable is coded -1 if the persons indicated that they increased the use of medications and/or added other treatment therapies over the 7-day trial period, 0 if they indicated no changes, +1 for decreased use and +2 if they eliminated medication use. Therefore, higher numbers indicate increased reduction in medication. The independent variables in this analysis were reduction in pain, age, gender, duration, baseline pain and the number of treatments used in the three different therapy classes, in other words, OTC analgesics, prescription analgesics and other treatments. The largest impact, as measured by the standardized coefficients, was reported reduction in pain $(p<0.0005)$. This estimated effect was three-times as great as initial baseline pain (which was negative, i.e., higher baseline pain subjects were less likely to reduce their medication all else equal), four-times as great as the negative effect of the number of prescription drugs initially taken (both significant at the 0.0005 level) and seven-times greater than the number of other treatments initially used $(\mathrm{p}<0.01)$. This latter effect was positive, in other words, those subjects using other pain therapies were more likely to reduce medication, with other factors unchanged. No other variables were significant at $\mathrm{p}<0.05$.

\section{- Device adverse effects}

No significant adverse events were reported. Adverse advents were increased pain in $1.5 \%$ of individuals and adverse reaction to the medical adhesive tape which was reported in less than $1 \%$ of individuals.

\section{Discussion}

Given the limitation of the study design, strong conclusions cannot be drawn as to the efficacy of the device used in this registry study. The limitations of the study are discussed further

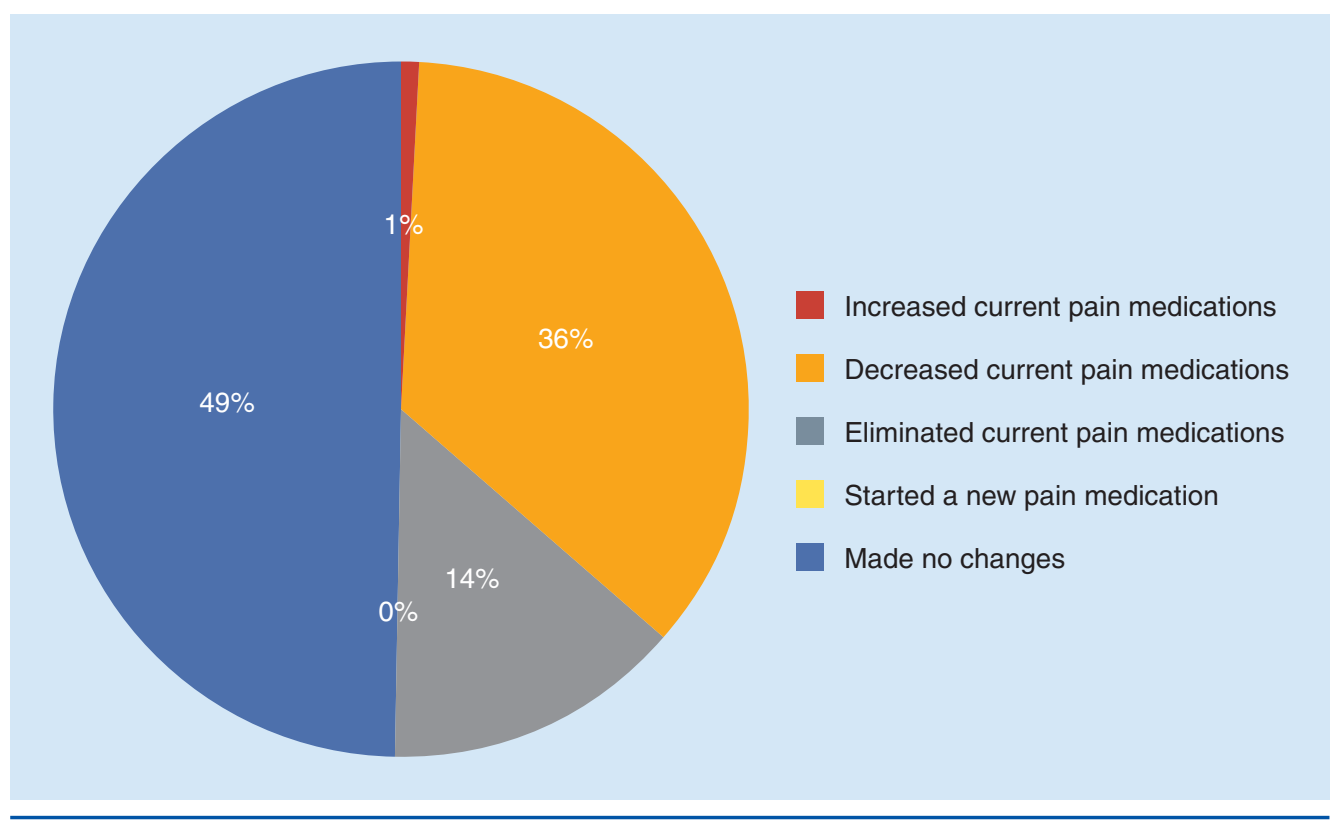

Figure 3. The percent of subjects who made changes in medication use during the 7-day trial: no change $(49 \%)$, increased $(0.6 \%)$, decreased (36\%), eliminated (14\%) and started a new medication $(0.3 \%)$. 


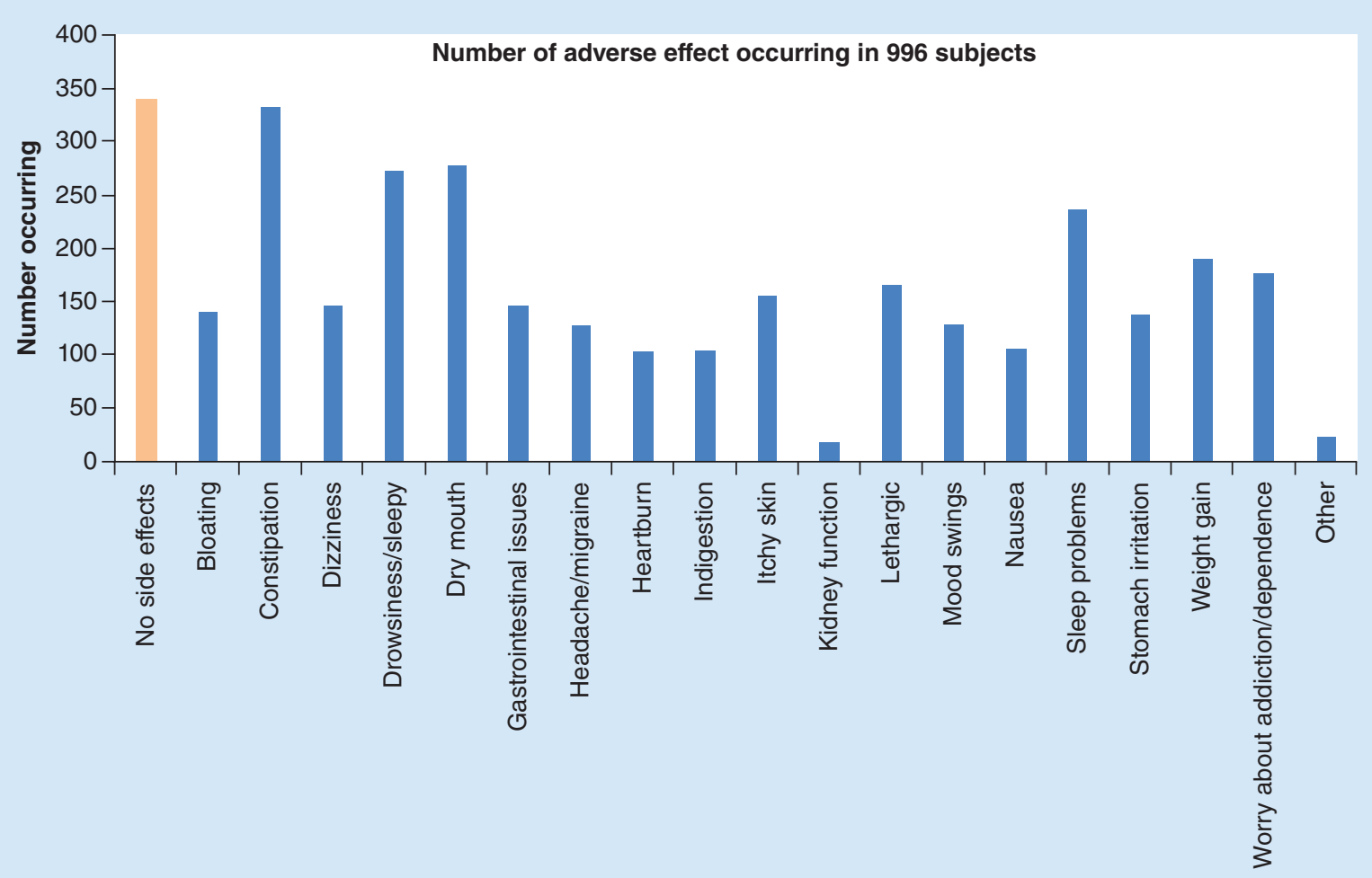

Figure 4. Types of adverse effects and the number who reported these effects for the $66 \%$ ( $n=658$ ) who reported having side effects. The mean number of adverse effects was 4.6 per subject.

below. However, this CBP registry study documents a number of important findings including the level of unresolved chronic pain in many individuals, significant adverse side effects from analgesic medications that impact patients' QoL and the potential of this new OTC pain therapy to help manage CBP.

The results presented here are consistent with, and others which compliment, the results of a prior published 5000 cohort registry study of chronic pain sufferers who used the same device [29]. However, the results from that study were not limited to back pain, nor did that study document detailed information on medication use, medication side effects or the negative impact of these medications on a person's QoL. The results are very similar across the two studies in terms of initial pain levels and pain reduction. In the prior study, the baseline mean VAS pain score was 8.02 and the average pain reduction was $37.9 \%$ [29]. In comparison, the current study found that the baseline mean VAS pain score was $8.04 \pm 1.46$ which decreased to $4.83 \pm 2.68$, or a $39.9 \%$ decrease, after using the trial device for 7 days. In addition, these reductions are consistent with two randomized

Table 7. Pain duration, analgesic use, percent subjects reporting adverse effects, mean adverse effects and their impact on patients' quality of life.

\begin{tabular}{|c|c|c|c|c|c|}
\hline Pain duration & $\begin{array}{l}\text { Mean number of } \\
\text { meds used }\end{array}$ & $\begin{array}{l}\text { Mean number of } \\
\text { prescription meds }\end{array}$ & $\begin{array}{l}\text { Percent of subjects } \\
\text { with adverse effects }\end{array}$ & $\begin{array}{l}\text { Mean number of adverse } \\
\text { effects (per subject) }\end{array}$ & Impact on QoL \\
\hline 6 months to 1 year & 2.29 & 1.19 & 48.2 & 4.3 & 4.2 \\
\hline $1-2$ years & 2.23 & 1.07 & 50 & 3.9 & 5.5 \\
\hline $2-5$ years & 2.48 & 1.45 & 68.3 & 4.1 & 5.6 \\
\hline $5-10$ years & 2.72 & 1.74 & 70.0 & 5.3 & 5.9 \\
\hline $10-20$ years & 2.63 & 1.64 & 76 & 4.8 & 5.8 \\
\hline 20 years + & 2.61 & 1.56 & 72 & 4.9 & 6.1 \\
\hline
\end{tabular}


Table 8. Subject age group, analgesic use, percent of subjects reporting adverse effects, mean adverse effects and their impact on patients' quality of life.

\begin{tabular}{|llllll|}
\hline Age (years) & $\begin{array}{l}\text { Mean number of } \\
\text { meds used }\end{array}$ & $\begin{array}{l}\text { Mean number of } \\
\text { prescription meds }\end{array}$ & $\begin{array}{l}\text { Percent of subjects } \\
\text { with adverse effects }\end{array}$ & $\begin{array}{l}\text { Mean number of adverse } \\
\text { effects (per subject) }\end{array}$ \\
\hline $25-34$ & 3.25 & 2.03 & 72.7 & 7.0 & 6.2 \\
\hline $35-44$ & 2.92 & 1.84 & 76.7 & 5.3 & 6.1 \\
\hline $45-55$ & 2.62 & 1.58 & 69.6 & 4.9 & 5.8 \\
\hline $56-64$ & 2.51 & 1.39 & 66.2 & 4.5 & 5.9 \\
\hline $65+$ & 2.08 & 1.18 & 55.6 & 3.2 & 5.0 \\
\hline QoL: Quality of life. & & & & \\
\hline
\end{tabular}

controlled trials (RCTs) that investigated the efficacy of the ActiPatch medical device in reducing chronic pain. In one such study that investigated the analgesic effect of the medical device for plantar fasciitis pain [27], the reported mean VAS score reduction was $40 \%$, while in the second study that investigated the analgesic effect in osteoarthritis of the knee [26], the reported mean VAS score reduction was 25\%.

In this study, the device was considered effective if the VAS pain score was reduced by at least $40 \%$. This $40 \%$ figure was chosen to account for a lack of a placebo control and reflects the fact that the two RCTs using this device reported placebo effects of 7 and 3\%, respectively [26,27]. Although the understanding of placebo has changed substantially and is now seen as being related to patient's perception of treatment, ways are being investigated to incorporate the placebo effect into medical treatment [30]. At this $40 \%$ effectiveness threshold, $52 \%$ of subjects reported effective pain relief and averaged a $66 \%$ reduction in their mean VAS scores. In the prior registry study of all chronic pain sufferers, a 2-point reduction on the mean VAS pain score was set as the threshold for effective pain relief. In that case, $65 \%$ met this 2-point or greater reduction threshold and reported a 57\% mean VAS reduction. Using this 2-point reduction for the current study, we find that $66 \%$ of the CBP subjects meet these criteria and average a $58 \%$ reduction in pain.

The high level of baseline pain in both registry studies, coupled with the high use of multiple therapies, indicates that many chronic pain sufferers have not been able to find adequate treatment from other available therapies. In addition, their willingness to purchase the trial unit indicates that they were still actively seeking solutions to find pain relief. This need for an adequate solution is also compatible with the finding that the majority of subjects $(60 \%)$ do not receive adequate pain relief from commonly used analgesics. This latter finding is similar to what was reported by the Arthritis UK/Daily Telegraph survey [24], which indicated that 54\% of chronic pain sufferers were not satisfied with the current pain treatment they were receiving from their GP or healthcare professional. Despite the fact that subjects in this study were using a wide range of analgesics from OTC to prescription drugs, averaging 2.5 analgesics per subject (including topical analgesics), they were unable to reduce their pain to acceptable levels. In addition, many subjects reported using nonanalgesic pain therapies such as TENS, heat wraps and physical therapy.

It is common knowledge that relying heavily on analgesic medications for pain control can result in adverse effects. This study indicates that $66 \%$ of the subjects experience adverse effects from their medications, averaging $4.6 \pm$ 3.3 per individual. Not surprisingly, there were correlations between the numbers of analgesics (both prescription and OTC) being used and the number of adverse effects being observed.

These findings are relevant, since they document the magnitude and implications of the adverse effects experienced by individuals using multiple analgesic medications in an attempt to control their chronic pain, outside of a controlled healthcare setting.

Also investigated was how these adverse effects impacted a subject's QoL on a $0-10$ scale. The regression results demonstrate that increases in adverse effects also tend to increase the negative impact on a person's QoL, even after controlling for the baseline measure of pain. Importantly, we found that the ActiPatch medical device was able to significantly reduce the pain level for the majority of subjects. We also find a strong relationship between this reduction in pain and the reduction or elimination of analgesic medication after the 7-day trial. Importantly, we find that less 
than $1 \%$ report increasing medication use or trying some new therapy while using the ActiPatch, thus indicating little or no adverse side effects of the treatment. This behavioral change in medication use gives credence to reported reductions in pain levels while the regression analyses make clear that this reduction in medication is also associated with an improvement in the subject's QoL by reducing adverse side effects.

\section{- Mechanism of action - negating central sensitization}

The biophysical and clinical community has been plagued for decades with a lack of a clear mechanism explaining how low power, PSWT can result in biological effects. With empirical evidence highlighting the therapeutic potential of the ActiPatch for chronic pain, there is a need to better understand how PSWT can provide analgesia. Recently, PSWT has been shown to regulate activity of peripheral afferents in the body through stochastic (random; stochastic neuromodulation is a process where subthreshold levels of input combine with resting 'afferent noise' to nondeterministically activate nerves), subsensory, neuromodulation [MCLeod KJ, Koneru SN, Unpublished Data], which indicates that the ActiPatch's analgesic effects occur through neuromodulation.

The CNS continuously receives large amounts of information from the periphery of the body and internal organs, including noxious, mechanical, chemical and motor/sensory stimuli. The background level of this activity is referred to as 'afferent noise' [31]. In order to appropriately process critical afferent inputs, the CNS must constantly adapt to the background levels of these inputs. In this way, differences from the background are easily detected and sent to the brain for processing. Habituation is the process by which sensation thresholds are raised, while the process of sensitization results in a lowering of sensation thresholds. Habituation and sensitization are normal physiologic processes that allow our nervous system to operate optimally. In the case of 'central sensitization,' the normal habituation/sensitization process has been disrupted such that even normal 'afferent noise' can be sensed as being painful. As such, when long-standing acute pain hypersensitizes the CNS, it results in increased pain facilitation pathways and decreased inhibition pathways [3235]. This results in pain that does not reduce over time (chronic) and therefore the sufferer is left in a persistent, sensitized state of pain. Central sensitization is now well established as an integral factor in many chronic pain states, including the commonly occurring knee and back pain $[32,34,35]$. Since peripheral information plays a crucial role in central sensitization, the key to reversing central sensitization, and moving the system out of the pain state, also lies in providing new peripheral information [33].

The challenge in re-establishing normal background pain threshold levels is that the most common means for stimulating musculoskeletal sensation is through movement or touch (e.g., manual therapy or exercise) [36]. But initiating an exercise regime is painful, and therefore it is a barrier to successful therapeutic activity [33], and this is compounded by the effect of chronic pain on the subjects' motivation [37]. There is some evidence that TENS can help reduce pain and hyperalgesia, while restoring healthy levels of central inhibition in patients with another clinical syndrome of central sensitization' fibromyalgia [38]. In other studies, TENS has been consistently shown to decrease central excitability and increase central inhibition [39-41], which are key to mitigating central sensitization. Complications such as discomfort from the tingling sensation, skin irritation from electrode gel and potential skin damage from electrical heating make prolonged TENS use inconvenient for long-term use. However, since sensory information constitutes only a fraction of all the 'afferent noise' that reaches the spinal cord [33], sensation-free neuromodulation has the potential to be used continuously for mitigating central sensitization. Given the sensation-free and contactless nature of the ActiPatch, it can be used to regulate peripheral afferent activity such that the CNS 'sees' an increase in nonsensory 'afferent noise' and, over time, raises the pain tolerance thresholds through the habituation process.

The prior and current registry studies [29] documented that pain relief associated with using the medical device often occurred over the course of days, with the majority of subjects reporting that it took up to 3 days to experience pain relief. These results indicate that the mechanism of action is unlikely a masking phenomenon. It has previously been proposed that chronic pain resulting from osteoarthritis of the knee may involve central sensitization [42-44]. In the knee osteoarthritis pain study [26] discussed earlier, when subjects were tested for pain pressure thresholds 
post-trial, the treatment group demonstrated a significantly higher pain tolerance than the placebo group, both locally and peripherally, indicating a decreased sensitivity to pain. This indicates that the repetitive input nature of the ActiPatch is indicative of a mechanism supporting reversal of central sensitization. Importantly, this could mean that ActiPatch therapy is not simply masking the underlying pain, as pain medications do, but is in fact, over time, treating the pain. However, this interesting possibility needs to be explored further in prospective clinical studies investigating long-term relief from chronic pain.

\section{- Study limitations}

The registry-style, self-reported method of data collection differs from methods used in randomized, blinded clinical studies. The strength of these data is that it is real world data that reflect a heterogeneous population of CBP sufferers who have turned to a new OTC therapy to combat long-standing CBP. However, we acknowledge that the study has many limitations which add caution to the findings presented in this study. As such, this study does not allow for causal statements since there is neither a positive or placebo-controlled group, nor it is possible to control and/or rule out other unobserved causal factors. However, the substantial decreases in pain seen in the study are unlikely to be entirely the result of the placebo effect for three reasons: the reduction in pain scores seen here are consistent with the results of prior responses acquired over a period of 2 years; published RCT studies that utilized the same device report that the associated placebo effect is relatively small $(<10 \%)$; and a longer term, registry study of 254 positive responders (i.e., those who indicated substantial 7-day relief) assessed over a 6-month period demonstrates the durability of the analgesic effect in a vast majority of the subjects $(>90 \%)$ as well as $>90 \%$ reporting improvements in QoL and continued decreased reliance on analgesic medications [45].

Another possible limitation of the study is the self-reported nature of the information collected since there is no way to check for consistency by accessing actual medical records. However, a statistically significant correlation is seen between the reported pain reduction and many behavioral variables that can be theoretically linked. For instance, those reporting higher decreases in pain were also more likely to reduce analgesic medication use, while those reporting more analgesic use were also more likely to report more adverse effects and a greater negative impact on QoL. Moreover, the core data collected by subjects over 2 years are consistent; for example, the baseline pain range on monthly averaged data over a 2-year period had been 7.91-8.29 VAS.

\section{Conclusion \& future perspective}

This registry study of 1394 CBP subjects indicates that $66 \%$ of subjects experience adverse effects from pain medications use, and these effects had a significant negative impact on their QoL. Furthermore, the perceived benefit of their analgesic therapy was found to be inadequate for the majority of individuals. After using the ActiPatch medical device for 7 days, $52 \%$ of these CBP subjects achieved a large and clinically significant pain reduction $(40 \%$ or more), with an average reduction of $66 \%$. Additionally, $49 \%$ of the CBP sufferers were able to reduce or eliminate their dependence on analgesic medications, which is consistent with the number who reported significant pain reduction. These results are encouraging, and need investigation in further RCTs, but imply that this new therapy can complement multimodal therapies for chronic pain patients, and in some cases, reduce the use of analgesic medications and in the process improve QoL of those suffering from CBP.

\section{Supplementary data}

To view the supplementary data that accompany this paper please visit the journal website at: www.futuremedicine. com/doilfull/10.2217/pmt-2016-0046

Financial \& competing interests disclosure

$R$ Staelin is Chairman of the Board of and an investor in BioElectronics Corporation. S Koneru is a paid employee of BioElectronics Corporation. I Rawe is a paid employee of BioElectronics Corporation. The authors have no other relevant affiliations or financial involvement with any organization or entity with a financial interest in or financial conflict with the subject matter or materials discussed in the manuscript apart from those disclosed.

No writing assistance was utilized in the production of this manuscript.

\section{Open access}

This work is licensed under the Creative Commons Attribution-NonCommercial 4.0 Unported License. To view a copy of this license, visit http://creativecommons.org/ licenses/by-nc-nd/4.0/ 


\section{References}

1 Tennant F, Hermann L. Intractable or chronic pain: there is a difference. West. J. Med. 173(5), 306 (2000).

2 Baker M, Collett B, Fischer A et al. Pain Proposal: Improving the Current and Future Management of Chronic Pain. A European Concensus Report. (2010). www.dgss.org/fileadmin/pdf/Pain_Proposal_ European_Consensus_Report.pdf

3 Breivik H, Collett B, Ventafridda V, Cohen R, Gallacher D. Survey of chronic pain in Europe: prevalence, impact on daily life, and treatment. Eur. J. Pain 10 (4), 287-333 (2006).

4 Gaskin DJ, Richard P. The economic costs of pain in the United States. J. Pain 13(8), 715-724 (2012).

5 Hong J, Reed C, Novick D, Happich M. Costs associated with treatment of chronic low back pain: an analysis of the UK General Practice Research Database. Spine (Phila PA 1976) 38(1), 75-82 (2013).

6 Phillips CJ. The cost and burden of chronic pain. Rev. Pain 3(1), 2-5 (2009).

7 Belsey J. Primary care workload in the management of chronic pain: a retrospective cohort study using a GP database to identify resource implications for UK primary care. J. Med. Econ. 5(1-4), 39-50 (2002).

8 Dale R, Stacey B. Multimodal treatment of chronic pain. Med. Clin. North Am. 100(1), 55-64 (2016).

9 Mathews M. Multimodal treatment of pain. Neurosurg. Clin. N. Am. 25(4), 803-808 (2014).

10 Mathews M, Davin S. Chronic pain rehabilitation. Neurosurg. Clin. N. Am. 25(4), 799-802 (2014).

11 Saragiotto BT, Machado GC, Ferreira ML, Pinheiro MB, Abdel Shaheed C, Maher CG. Paracetamol for low back pain. Cochrane Database Syst. Rev. 6, CD012230 (2016).

12 Enthoven WT, Roelofs PD, Deyo RA, Van Tulder MW, Koes BW. Non-steroidal anti-inflammatory drugs for chronic low back pain. Cochrane Database Syst. Rev. 2, CD012087 (2016).

13 Moore RA, Derry S, Aldington D, Cole P, Wiffen PJ. Amitriptyline for neuropathic pain in adults. Cochrane Database Syst. Rev. 7 , CD008242 (2015).

14 Rej S, Dew MA, Karp JF. Treating concurrent chronic low back pain and depression with low-dose venlafaxine: an initial identification of 'easy-to-use' clinical predictors of early response. Pain Med. 15(7), 1154-1162 (2014).
15 Vyvey M. Steroids as pain relief adjuvants. Can. Fam. Physician 56(12), 1295-1297, e1415 (2010).

16 Wiffen P, Collins S, Mcquay H, Carroll D, Jadad A, Moore A. Anticonvulsant drugs for acute and chronic pain. Cochrane Database Syst. Rev. 3, CD001133 (2005).

17 Wiffen PJ, Mcquay HJ, Edwards JE, Moore RA. Gabapentin for acute and chronic pain. Cochrane Database Syst. Rev. 3, CD005452 (2005).

18 Deyo RA, Von Korff M, Duhrkoop D. Opioids for low back pain. BMJ 350, g6380 (2015).

19 Carter GT, Duong V, Ho S, Ngo KC, Greer CL, Weeks DL. Side effects of commonly prescribed analgesic medications. Phys. Med. Rehabil. Clin. N. Am. 25(2), 457-470 (2014).

20 Labianca R, Sarzi-Puttini P, Zuccaro SM, Cherubino P, Vellucci R, Fornasari D. Adverse effects associated with non-opioid and opioid treatment in patients with chronic pain. Clin. Drug Investig. 32 (Suppl. 1), 53-63 (2012).

21 Woodcock J. A difficult balance - pain management, drug safety, and the FDA. $N$. Engl. J. Med. 361(22), 2105-2107 (2009).

22 Foundation USP. Educating consumers on choosing and using OTC pain relievers responsibly. www.uspainfoundation.org/awareness/

23 Dworkin RH, Turk DC. Accelerating the development of improved analgesic treatments: the ACTION public-private partnership. Pain Med. 12(Suppl. 3), S109-S117 (2011).

24 Arthritis UK. New survey highlights severe impact of arthritis pain on daily life - but there is hope.

www.arthritisresearchuk.org

25 Koneru SN, Westgate CR, McLeod KJ. Rectification of RF fields in load dependent coupled systems: application to non-invasive electroceuticals. J. Biomed. Sci. Eng. 9, 112-121 (2016).

26 Bagnato GL, Miceli G, Marino N, Sciortino D, Bagnato GF. Pulsed electromagnetic fields in knee osteoarthritis: a double blind, placebo-controlled, randomized clinical trial. Rheumatology (Oxford) 55(4), 755-762 (2016).

27 Brook J, Dauphinee DM, Korpinen J, Rawe IM. Pulsed radiofrequency electromagnetic field therapy: a potential novel treatment of plantar fasciitis. J. Foot Ankle Surg. 51(3), 312-316 (2012).

28 Rawe IM, Lowenstein A, Barcelo CR, Genecov DG. Control of postoperative pain with a wearable continuously operating pulsed radiofrequency energy device: a preliminary study. Aesthetic Plast. Surg. 36(2), 458-463 (2012).

29 Rawe IM, Kotak DC. A UK registry study of the effectiveness of a new over-the-counter chronic pain therapy. Pain Manag. 5(6), 413-423 (2015).

30 Carvalho C, Caetano JM, Cunha L, Rebouta P, Kaptchuk TJ, Kirsch I. Open-label placebo treatment in chronic low back pain: a randomized controlled trial. Pain 157(12), 2766-2772 (2016).

31 Gillespie JI, Van Koeveringe GA, De Wachter $S G$, De Vente J. On the origins of the sensory output from the bladder: the concept of afferent noise. BJU Int. 103(10), 1324-1333 (2009).

32 Clauw DJ. Diagnosing and treating chronic musculoskeletal pain based on the underlying mechanism(s). Best Pract. Res. Clin. Rheumatol. 29(1), 6-19 (2015).

33 Nijs J, Paul Van Wilgen C, Van Oosterwijck $\mathrm{J}$, Van Ittersum $\mathrm{M}$, Meeus $\mathrm{M}$. How to explain central sensitization to patients with 'unexplained' chronic musculoskeletal pain: practice guidelines. Man. Ther. 16(5), 413-418 (2011).

34 Reynolds WS, Dmochowski R, Wein A, Bruehl S. Does central sensitization help explain idiopathic overactive bladder? Nat. Rev. Urol. 13(8), 481-491 (2016).

35 Woolf CJ. Central sensitization: implications for the diagnosis and treatment of pain. Pain 152(Suppl. 3), S2-S15 (2011).

36 Mior S. Exercise in the treatment of chronic pain. Clin. J. Pain 17(Suppl. 4), S77-S85 (2001)

37 Schwartz N, Temkin P, Jurado S et al. Chronic pain. Decreased motivation during chronic pain requires long-term depression in the nucleus accumbens. Science 345(6196), 535-542 (2014).

38 Dailey DL, Rakel BA, Vance CG et al. Transcutaneous electrical nerve stimulation reduces pain, fatigue and hyperalgesia while restoring central inhibition in primary fibromyalgia. Pain 154(11), 2554-2562 (2013).

39 Desantana JM, Da Silva LF, De Resende MA, Sluka KA. Transcutaneous electrical nerve stimulation at both high and low frequencies activates ventrolateral periaqueductal grey to decrease mechanical hyperalgesia in arthritic rats. Neuroscience 163(4), 1233-1241 (2009).

40 Kalra A, Urban MO, Sluka KA. Blockade of opioid receptors in rostral ventral medulla prevents antihyperalgesia produced by 
transcutaneous electrical nerve stimulation (TENS). J. Pharmacol. Exp. Ther. 298(1), 257-263 (2001).

41 Ma YT, Sluka KA. Reduction in inflammation-induced sensitization of dorsal horn neurons by transcutaneous electrical nerve stimulation in anesthetized rats. Exp. Brain Res. 137(1), 94-102 (2001).

42 Bartley EJ, King CD, Sibille KT et al. Enhanced pain sensitivity among individuals with symptomatic knee osteoarthritis: potential sex differences in central sensitization. Arthritis Care Res. (Hoboken) 68(4), 472-480 (2016).

43 Campbell CM, Buenaver LF, Finan P et al. Sleep, pain catastrophizing, and central sensitization in knee osteoarthritis patients with and without insomnia. Arthritis Care Res. (Hoboken) 67(10), 1387-1396 (2015).
44 Lluch E, Torres R, Nijs J, Van Oosterwijck J. Evidence for central sensitization in patients with osteoarthritis pain: a systematic literature review. Eur. J. Pain 18(10), 1367-1375 (2014).

45 Rawe I. A registry study to assess the durability of ActiPatch ${ }^{\circledR}$ - a novel OTC neuromodulation therapy for chronic pain. Br. J. Pain 10 (2 Suppl. 1), 62-63 (2016). 